IF. Sér. Reg. n. 54 p. 45-57 maio 2016

http://dx.doi.org/10.4322/ifsr.2016.004

ISSN on-line 2179-2372

\title{
EDUCAÇÃO AMBIENTAL NA ESTAÇÃO ECOLÓGICA DE PARANAPANEMA, ESTADO DE SÃO PAULO, BRASIL ${ }^{1}$
}

\section{ENVIRONMENTAL EDUCATION IN PARANAPANEMA ECOLOGICAL STATION, SÃO PAULO STATE, BRAZIL}

\author{
Sueli HERCULIANI ${ }^{2,}$; Marilda Rapp de ESTON²; Waldir Joel de ANDRADE; \\ Paulo Henrique dos SANTOS ${ }^{2}$; Rosângela Célia Ribeiro de OLIVEIRA²; Fernando DESCIO²
}

\begin{abstract}
RESUMO - A Estação Ecológica de Paranapanema - E.Ec. Paranapanema é uma Unidade de Conservação de Proteção Integral. Ocupa uma área de 635,20 hectares e está situada no município de Paranapanema, no Estado de São Paulo, sendo gerenciada pelo Instituto Florestal. Os objetivos deste trabalho foram identificar a potencialidade da Estação Ecológica com relação ao meio natural, as estruturas físicas e os recursos humanos existentes, necessários para a implantação do Subprograma de Educação Ambiental. Para a obtenção dos dados primários, foram realizadas entrevistas semiestruturadas, aplicadas junto ao gestor da Unidade. Visitas técnicas na Estação Ecológica para análise da infraestrutura existente e da potencialidade de desenvolver atividades de educação ambiental na área foram também realizadas. Para a obtenção dos dados secundários, foi feita uma revisão dos materiais bibliográficos. A pesquisa revelou que na E.Ec. Paranapanema a infraestrutura física para o desenvolvimento de atividades de educação ambiental é quase inexistente, havendo somente uma trilha interpretativa e faltam recursos humanos para o desenvolvimento desta atividade. Assim, são fornecidas propostas para a implantação de um Subprograma de Educação Ambiental nessa Unidade de Conservação.
\end{abstract}

Palavras-chave: Unidade de Conservação; Uso Público; conscientização; meio ambiente.

\begin{abstract}
The Paranapanema Ecological Station is an Integral Protection Conservation Unit. It covers an area of 635.20 hectares, in the municipality of Paranapanema in São Paulo state, managed by the Forestry Institute. The objectives of this study were to identify the potential of Paranapanema Ecological Station in relation to the natural environment, the physical structures and human resources required for the implementation of Environmental Education Subprogram. In order to obtain the primary data, semi-structured interviews were conducted, applied to the unit manager. We also carried out technical visits to analyze the existing infrastructure and the capability to develop environmental education activities in the area. To obtain the secondary data a review of bibliographic material was performed. The survey revealed that the E.Ec. Paranapanema physical infrastructure for the development of environmental education is almost non-existent, with only an interpretive trail and the it lacks human resources for the development of this activity. Thus, proposals are provided for the Environmental Education Subprogram in this Conservation Unit.
\end{abstract}

Keywords: Conservation Unit; Public Use; awareness; environment.

\footnotetext{
$\overline{1}$ 1Artigo científico. Recebido para análise em 29.12.2015. Aceito para publicação em 09.05.2016. Publicado on-line em 15.06.2016. 


\section{INTRODUÇÃO}

As primeiras pretensões na criação de áreas legalmente protegidas para resguardar os ecossistemas e as paisagens naturais ocorreram no século XIX, tendo sido criado, em 1872, nos Estados Unidos, o Parque Nacional de Yellowstone, o primeiro no mundo (Yellowstone Association, 2014).

No Brasil, a primeira Unidade de Conservação foi criada, em 1937, na Serra da Mantiqueira, o Parque Nacional de Itatiaia. Este abrange os municípios de Itatiaia e Resende, no Estado do Rio de Janeiro, e Bocaina de Minas e Itamonte, no Estado de Minas Gerais (Instituto Chico Mendes de Conservação da Biodiversidade - ICMBio, 2015).

A iniciativa de criação de parques nacionais difundiu-se por vários países. Com a Conferência das Nações Unidas sobre o Meio Ambiente ou Declaração de Estocolmo, formalizou-se, em 1972, a preocupação de grande parte dos países com as questões relacionadas ao meio ambiente (Declaração..., 1972).

Em decorrência da Conferência de Estocolmo, a Organização das Nações Unidas para a Educação, Ciência e Cultura - UNESCO promoveu, em 1975, em Belgrado (atual Sérvia), o Encontro Internacional em Educação Ambiental, no qual foi criado o Programa Internacional de Educação Ambiental - PIEA. Foram estabelecidos os princípios de que a educação ambiental deve ser continuada, multidisciplinar, integrada às diferenças regionais e voltada aos interesses nacionais (Encontro..., 1975).

Em Tbilisi (atual Geórgia), em 1977, ocorreu outro marco importante, que foi a Conferência Intergovernamental sobre Educação Ambiental, também organizada pela UNESCO. Considerou-se que a Educação Ambiental deve ser orientada para solucionar problemas através da participação ativa dos atores da educação. $\mathrm{O}$ foco interdisciplinar deve ser empregado e deve-se construir um processo contínuo e permanente, iniciando-se na educação infantil e continuando através de todas as fases do ensino formal e não formal (Conferência..., 1977).

No Brasil, somente em 1988, a Constituição da República (CF/88), dedicou o Capítulo VI ao Meio Ambiente. No seu Art. 225, Inciso VI, determinou que cabe ao "[...] Poder Público, promover a Educação Ambiental em todos os níveis de ensino [...]" (Brasil, 1988).

Com a realização da Conferência sobre Meio Ambiente e Desenvolvimento, em junho de 1992, conhecida como RIO-92/ECO-92 (Conferência..., 1992) foram elaborados documentos de extrema importância no tocante às questões ambientais, tais como o Tratado da Educação Ambiental (Tratado de Educação Ambiental, 1992) e a Agenda 21 (Agenda 21, 1992).

Com a promulgação da Lei no 9795/99 foi instituída a Política Nacional de Educação Ambiental e estabelecido que o Poder Público deve incentivar a participação de empresas públicas e privadas no desenvolvimento de programas de Educação Ambiental. Também cabe ao Poder Público promover a sensibilização da sociedade para a importância das Unidades de Conservação (Brasil, 1999).

A partir da promulgação da Lei $n^{\circ}$ 9.985/2000, que instituiu o Sistema Nacional de Unidades de Conservação da Natureza - SNUC, tornou-se possível uma melhor gestão de áreas protegidas (Brasil, 2000).

Com a criação do Sistema Estadual de Florestas do Estado de São Paulo - SIEFLOR, através do Decreto Estadual $\mathrm{n}^{0} 51.543 / 2006$, estabeleceu-se ser um dos principais objetivos do Programa de Uso Público despertar a consciência crítica para a importância da conservação nas Unidades de Conservação de Proteção Integral, bem como a participação ativa da sociedade (São Paulo, 2006). Outra medida importante relacionada à Educação Ambiental foi a regulamentação do Uso Público em Unidades de Conservação (São Paulo, 2008).

O Programa de Uso Público do Instituto Florestal tem como um dos objetivos desenvolver atividades de educação ambiental junto à comunidade, bem como despertar a consciência crítica para a necessidade de conservação dos atributos naturais das Unidades de Conservação sob sua administração (Cervantes et al., 1992).

A categoria Estação Ecológica é uma Unidade de Proteção Integral que tem por objetivo a preservação da natureza e a realização de pesquisas científicas. É proibida a visitação pública, exceto quando com objetivo educacional, de acordo com o que dispuser o Plano de Manejo da Unidade ou regulamento específico (Brasil, 1991). 
Uma área situada no distrito e município de Paranapanema, necessária ao Serviço Florestal da Secretaria da Agricultura, foi declarada de utilidade pública em 1962, através do Decreto Estadual n 40.992 (São Paulo, 1962). Essa área passou a ser denominada Floresta Estadual de Paranapanema. Em 1993, foram desmembrados 635,20 hectares dessa Floresta, criando-se a Estação Ecológica de Paranapanema, por meio do Decreto Estadual $\mathrm{n}^{\circ} 37.538$, com a finalidade de melhor proteger um dos últimos remanescentes da Floresta Estacional Semidecidual do sudoeste paulista (São Paulo, 1993).

A Floresta Estadual e a Estação Ecológica de Paranapanema são duas unidades de conservação, as quais estão territorialmente integradas, contudo são unidades que possuem objetivos de manejo diferenciados. A Floresta Estadual, por ser uma unidade de conservação de uso sustentável, tem como principal objetivo a produção florestal, que neste caso é principalmente a produção de madeira e resina de Pinus. Já a Estação Ecológica, por ser uma unidade de conservação de proteção integral, tem como um dos objetivos básicos de manejo o desenvolvimento de atividades de pesquisa e educação ambiental (Aoki et al., 2001).

Os objetivos deste trabalho foram identificar a potencialidade da Estação Ecológica com relação ao meio natural, as estruturas físicas e recursos humanos existentes, necessários ao Subprograma de Educação Ambiental, como estratégia de conservação para a Unidade.

\section{MATERIAL E MÉTODOS}

A Estação Ecológica de Paranapanema está localizada no sudoeste do estado de São Paulo (Figura 1), ocupa uma área de 635,20 hectares, é recoberta por Floresta Estacional Semidecidual e apresenta altitude média de $630 \mathrm{~m}$ (Aoki et al., 2001). O clima é considerado Cfa, quente de inverno seco com temperatura média mensal máxima de $22{ }^{\circ} \mathrm{C}$ e média mensal mínima de $18{ }^{\circ} \mathrm{C}$ (Ventura et al., 1965). Essa Estação Ecológica é uma Unidade de Conservação de Proteção Integral e é contígua à Floresta Estadual de Paranapanema, que é uma Unidade de Uso Sustentável.

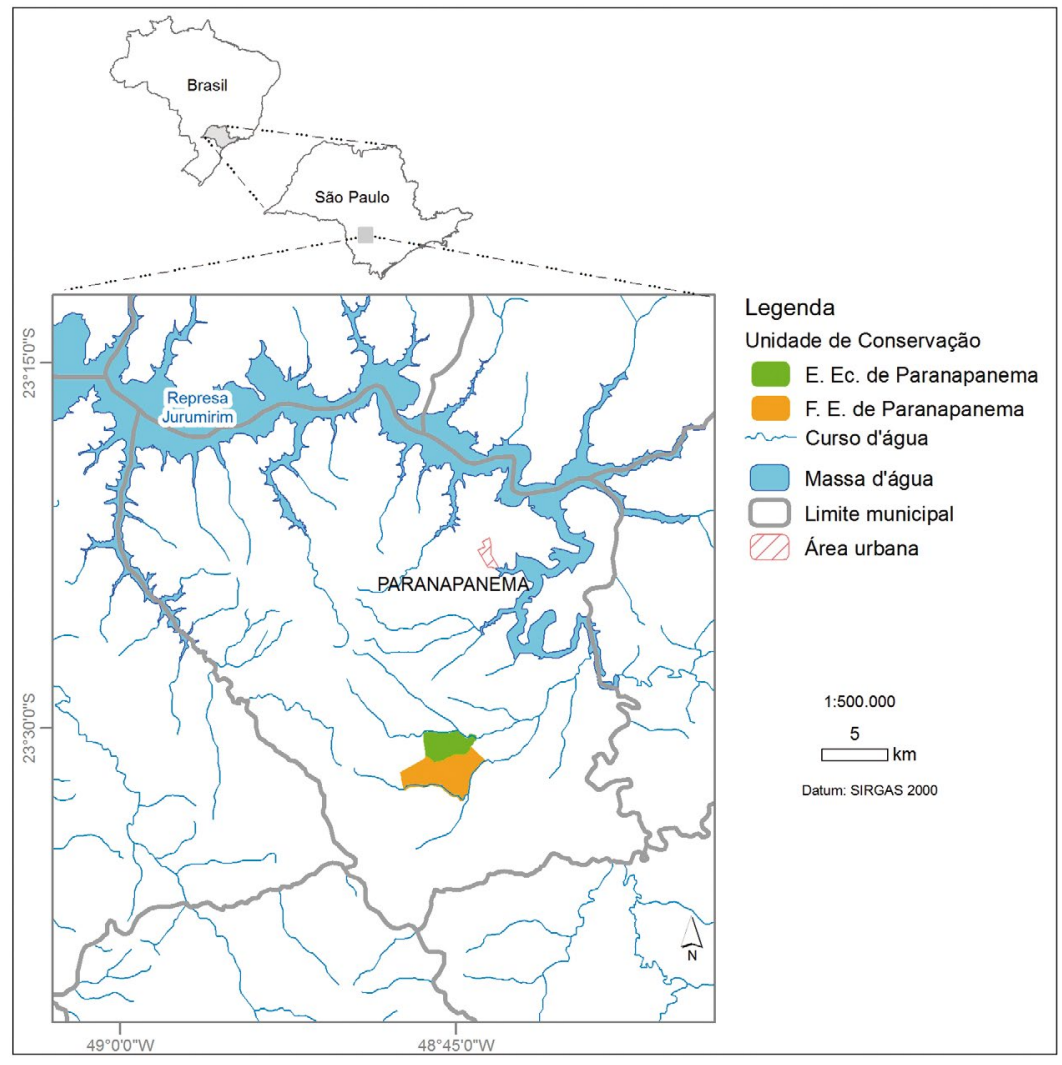

Figura 1. Localização da área de estudo.

Figure 1. Location of study area. 
A Estação Ecológica de Paranapanema, situada no município de mesmo nome, no Estado de São Paulo, é uma unidade integrante do Sistema Estadual de Florestas do Estado de São Paulo - SIEFLOR (São Paulo, 2006).

Para a obtenção dos dados primários, foram realizadas entrevistas semiestruturadas, baseando-se no roteiro recomendado por Lüdke e André (1986) (Apêndice), aplicadas junto ao responsável pela Estação Ecológica de Paranapanema, com o objetivo de verificar as condições desta Unidade de Conservação para o desenvolvimento de atividades de educação ambiental. Foram realizadas também visitas técnicas para análise da infraestrutura existente e da potencialidade da área. Para a obtenção dos dados secundários, foi realizada uma revisão dos materiais bibliográficos existentes sobre a Unidade e a legislação pertinente.

\section{RESULTADOS E DISCUSSÃO}

A pesquisa revelou que a Estação Ecológica de Paranapanema não dispõe de infraestrutura física completa para o desenvolvimento de atividades de educação ambiental, enquanto a Floresta Estadual, Unidade de Uso Sustentável contígua à área, dispõe de algumas estruturas físicas adequadas ao desenvolvimento de um Subprograma de Educação Ambiental. Propõe-se que essas estruturas da Floresta Estadual sejam utilizadas no âmbito do Subprograma de Educação Ambiental da E.Ec. Paranapanema. A integração das duas Unidades permitirá aos visitantes ter melhor entendimento das diferentes e nobres finalidades das duas áreas, enriquecendo, assim, os projetos de educação ambiental.

Atividades de educação ambiental de forma integrada, utilizando a Floresta Estadual e a Estação Ecológica de Paranapanema, já ocorrem desde 2006. A entrevista aplicada ao gestor da Unidade também revelou que foi implantado de outubro de 2009 até fevereiro de 2012 um projeto de educação ambiental denominado Criança Ecológica - Floresta Legal, integrante do Programa Município Verde-Azul, da Secretaria do Meio Ambiente do Estado.

O projeto atendia alunos das redes públicas de ensino municipal, estadual e particular, nas idades de 8 a 10 anos. O público escolar era recepcionado nas dependências da Floresta Estadual de Paranapanema. Num espaço pedagógico, eram desenvolvidas palestras e atividades lúdicas como jogos e brincadeiras. Os temas abordados tratavam de noções sobre aquecimento global, uso racional da água, reciclagem do lixo, poluição, importância da fauna e da flora, desenvolvimento sustentável e outros condizentes com a relação homem-ambiente.

Os visitantes recebiam também materiais didáticos, tais como livro temático, adesivos e bottons. Visitavam a Trilha Interpretativa dos Jerivás, na Estação Ecológica, quando eram tratados temas relacionados à importância da conservação das florestas.

Entre os vários materiais confeccionados, foi editado o livro didático denominado Criança Ecológica: sou dessa turma (Graziano e Lima, 2009) e monitores foram contratados e treinados especificamente para o Projeto, que integrava um dos 21 Projetos Ambientais Estratégicos do Governo do Estado. Esse trabalho, que também ocorreu em outras Unidades de Conservação do Instituto Florestal, e tinha como objetivo sensibilizar e despertar nas crianças atitudes capazes de contribuir com a melhoria da qualidade de vida e do meio ambiente, foi interrompido em 2012 devido às mudanças de gestão do Governo Estadual, quando se acabaram os recursos para o desenvolvimento dessas atividades de educação ambiental.

A falta de pessoal e recursos na Estação Ecológica de Paranapanema inviabiliza, atualmente, a implantação e o desenvolvimento de um Subprograma de Educação Ambiental. É imprescindível a contratação de um quadro de monitores/estagiários, cursando os níveis médio e superior de ensino, devidamente capacitados e atualizados por meio de cursos de formação, que possam atuar com educação ambiental.

Em relação às estruturas existentes nas duas Unidades de Conservação para atividades de educação ambiental verificou-se que estas se complementam (Tabela 1). 
Tabela 1. Estruturas existentes na Estação Ecológica e na Floresta Estadual de Paranapanema para o Subprograma de Educação Ambiental.

Table 1. Structures in the Ecological Station and Paranapanema State Forest to the Environmental Education Subprogram.

\begin{tabular}{lcc}
\hline Estruturas & Estação Ecológica & Floresta Estadual \\
\hline Centro de Visitantes & & $\mathrm{X}$ \\
Sanitários públicos & & $\mathrm{X}$ \\
Espaço multiuso & & $\mathrm{X}$ \\
Placas indicativas & $\mathrm{X}$ & \\
Trilhas interpretativas & $\mathrm{X}$ & \\
\hline
\end{tabular}

Um Centro de Visitantes é importante para o desenvolvimento do Subprograma de Educação Ambiental. É um edifício construído com a finalidade de recepcionar o visitante e informá-lo sobre as oportunidades que a área oferece. Tem como objetivo, também, desenvolver atividades interpretativas, educativas e culturais sobre os recursos e possíveis problemas ambientais da área silvestre e da região, devendo, também, incentivar a visita a outras áreas silvestres (Marcondes et al., 2008). Como a Estação Ecológica de Paranapanema não dispõe de Centro de Visitantes, poder-se-ia utilizar o já existente na Floresta Estadual (Figura 2).

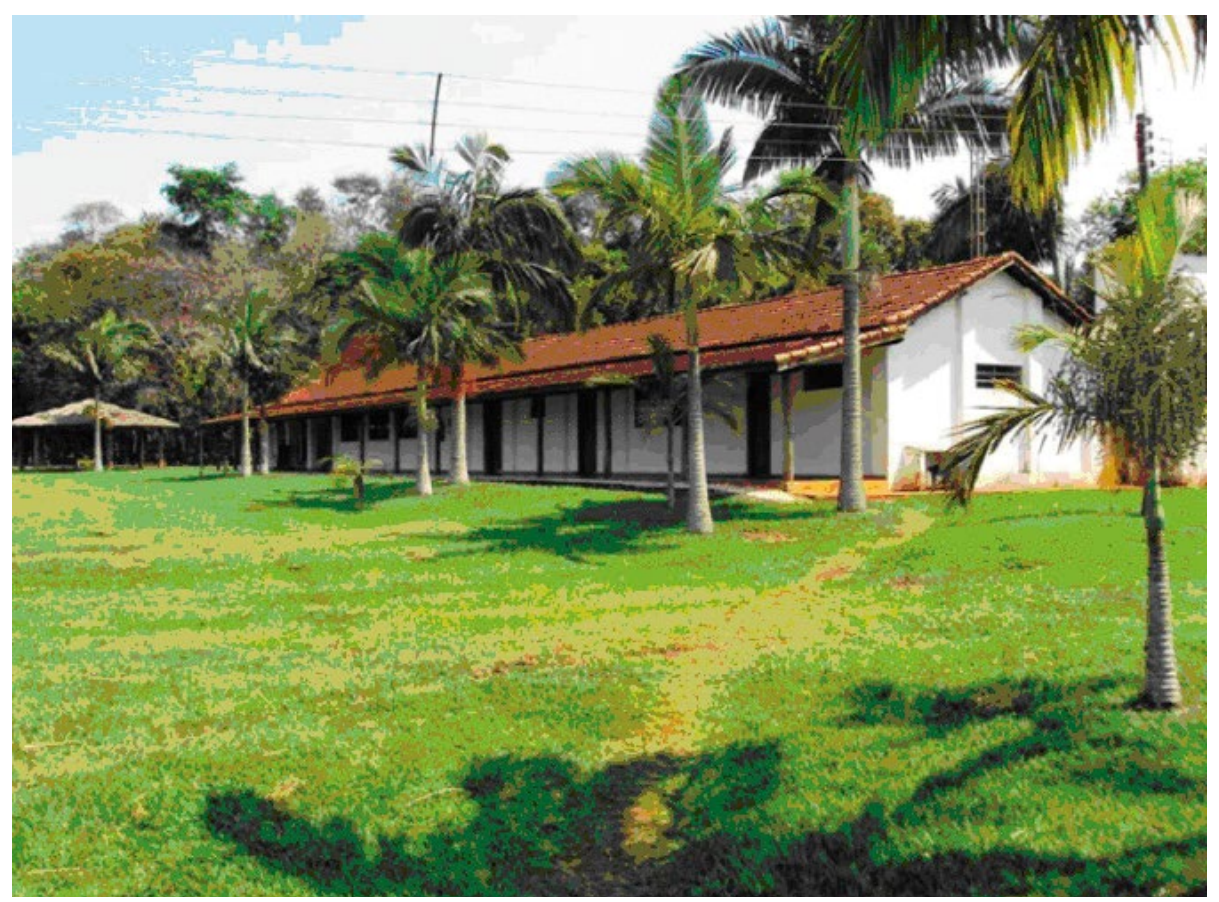

Figura 2. Centro de Visitantes - Floresta Estadual de Paranapanema.

Figure 2. Visitor Center - Paranapanema State Forest.

Para o subprograma de Educação Ambiental da Estação Ecológica de Paranapanema outras estruturas também são importantes, tais como:

a) instalação de sanitários e bebedouros que atendam às Normas da Associação Brasileira de Normas Técnicas - ABNT, Norma Brasileira - NBR 9050. Esta trata sobre acessibilidade a edificações, mobiliário, espaço e equipamentos (Associação Brasileira de Normas Técnicas - ABNT, 2015);

b) instalação de um espaço multiuso para atividades diversas com estudantes, com bancos e mesas. Na Floresta Estadual já existe um espaço para esse fim, que poderia ser utilizado devido à proximidade da área; c) dotação da área de todos os cuidados relacionados à segurança dos visitantes e funcionários; 
d) confecção de materiais de divulgação, tais como fôlderes e cartazes, considerando os diversos perfis de público;

e) confecção de mais placas informativas e indicativas, além das já existentes na Estação Ecológica;

f) implantação de outras trilhas interpretativas levando-se em conta as características dos vários grupos a serem atendidos.

A interpretação em áreas naturais é uma estratégia educativa que contribui para a preservação das Unidades de Conservação. Uma trilha é considerada interpretativa quando seus recursos são traduzidos para o visitante através de guias especializados, folhetos ou painéis (Vasconcellos, 2006). É considerada um importante instrumento para o desenvolvimento dos programas de educação ambiental, auxiliando na assimilação do conhecimento sobre as relações que ocorrem na natureza e sensibilizando os visitantes acerca da importância das áreas e recursos naturais (Toledo e Pelicioni, 2005). Proporciona ao público, de modo especial às crianças e adolescentes, uma aproximação à realidade dos assuntos estudados, preenchendo as lacunas de um ensino excessivamente teórico (Guillaumon et al., 1977). O fato de a Estação Ecológica e a Floresta Estadual de Paranapanema serem duas Unidades de Conservação contíguas, com vegetação tão distinta, enriquece muito o conteúdo a ser abordado.

A Estação Ecológica de Paranapanema já dispõe de uma trilha de interpretação da natureza denominada Trilha dos Jerivás, com 570 metros de extensão, dotada de diversas placas de identificação das espécies arbóreas. A trilha recebeu esse nome porque em grande parte de seu percurso existem concentrações de uma palmeira, popularmente conhecida como jerivá, cujo nome científico é Syagrus romanzoffiana. A diversidade de espécies presentes na trilha proporciona e enriquece a abordagem dos temas ambientais (Figura 3).

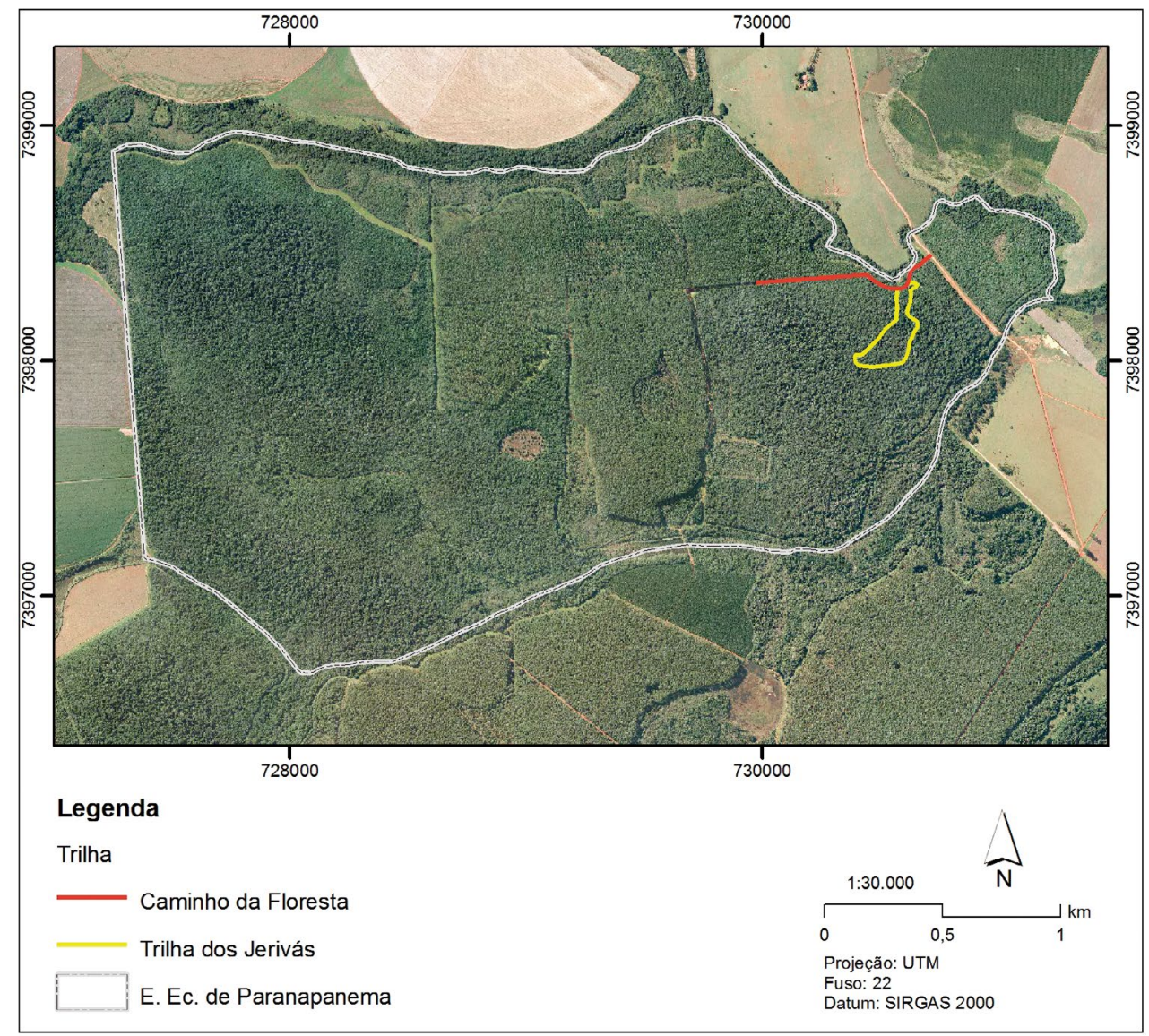

Figura 3. Trilhas de interpretação da natureza na Estação Ecológica.

Figure 3. Nature interpretation trails in the Ecological Station. 
Propõe-se, também, a implantação de outro caminho para interpretação (Figura 3), que seria o aproveitamento da estrada de terra, que se inicia junto ao portão da entrada da Estação Ecológica (Figura 4), com visando ao atendimento de públicos específicos, tais como: crianças na primeira infância, especiais, pessoas com mobilidade reduzida e idosos. Esse caminho poderia receber a denominação de "Caminho da Floresta".

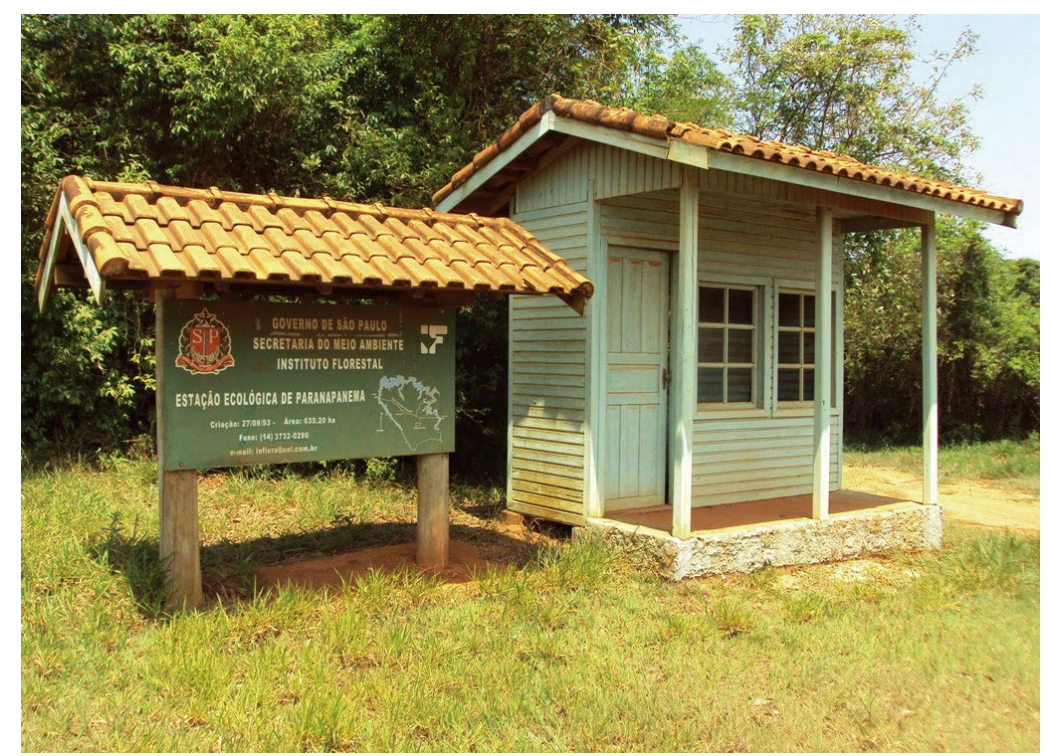

Figura 4. Entrada da Estação Ecológica de Paranapanema.

Figure 4. Entrance of Paranapanema Ecological Station.

Para tanto, é necessária a implantação de placas e painéis interpretativos para realçar as diferenças de vegetação (nativa e exótica) (figuras 5 e 6), entre outros aspectos. Andrade e Rocha (2008) recomendam a criação de roteiros interpretativos para trilhas e estes devem ser coerentes e eficientes, baseados nos diferentes aspectos existentes e nas principais informações e conceitos a serem transmitidos.

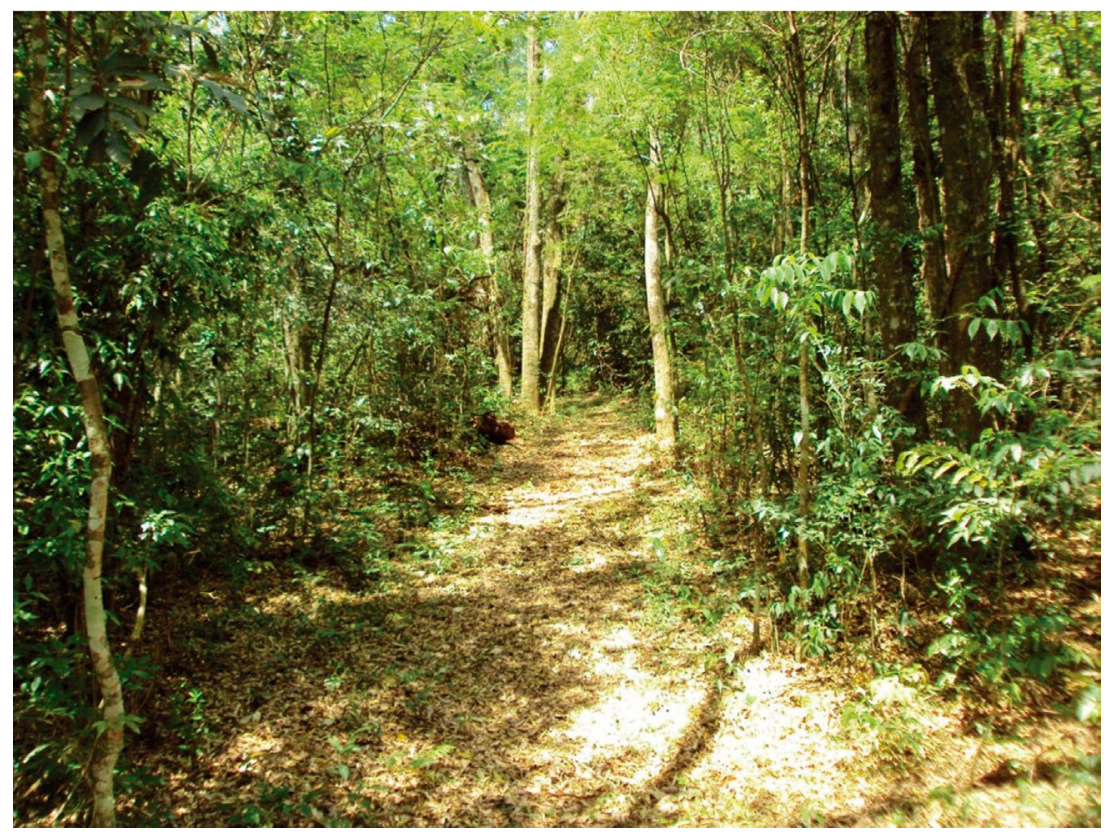

Figura 5. Aspectos da vegetação natural da Estação Ecológica.

Figure 5. Natural vegetation aspects of the Ecological Station. 


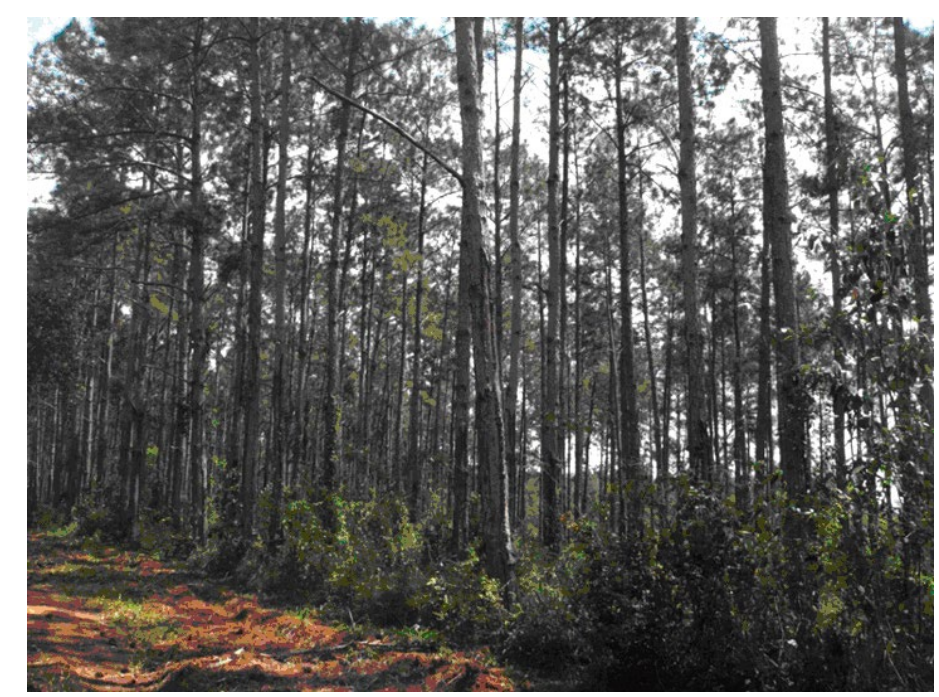

Figura 6. Plantio de Pinus na Estação Ecológica.

Figure 6. Pine planting in the Ecological Station.

$\mathrm{Na}$ área onde está localizado o rio, há também o potencial de ser instalado um deque, com gradil de proteção para a segurança dos usuários, para permitir a apreciação e observação da flora e fauna local (Figura 7).

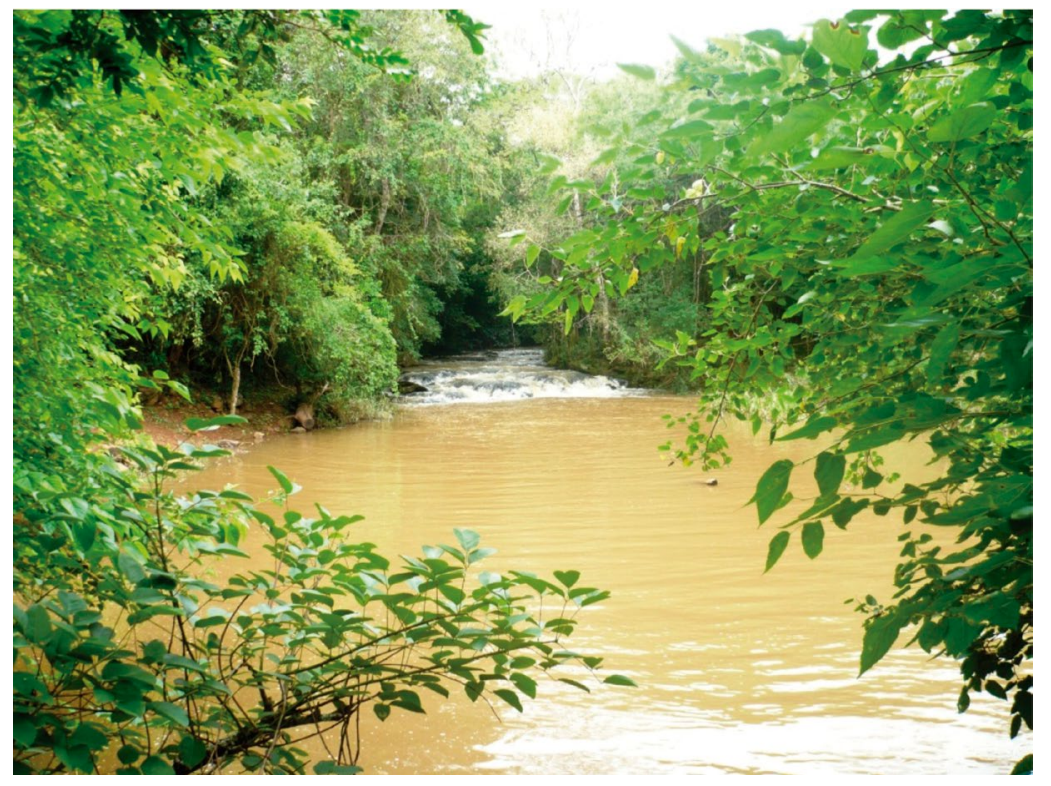

Figura 7. Local onde se sugere a implantação de um deck para atividades de contemplação.

Figure 7. Place for the implementation of a deck for contemplation activities.

Promover a educação e interpretação ambiental é um dos objetivos do Sistema Nacional de Unidades de Conservação da Natureza (Brasil, 2000). É importante que projetos de Educação Ambiental específicos para o público das escolas localizadas na zona de entorno sejam desenvolvidos, e devem estar articulados com as Diretrizes para Estratégia Nacional de Comunicação e Educação Ambiental em Unidades de Conservação - ENCEA (Brasil, 2009). Nesses projetos os educandos poderão realizar atividades diversas na Estação Ecológica mediante prévio agendamento. De acordo com Herculiani et al. (2009), projetos educacionais de longo prazo, prioritariamente junto às escolas que estão muito próximas, mostrando a importância da Unidade de Conservação, ajudam a preservá-la. 
É importante que sejam ministrados aos professores das escolas da região cursos de formação em educação ambiental, com o objetivo de capacitá-los para o desenvolvimento de atividades de educação ambiental na Estação Ecológica de Paranapanema.

A proximidade da Estação Ecológica com atividades de agricultura indica também a premência para o desenvolvimento de projetos e programas educativos com a população localizada no entorno da Unidade. Segundo Tabanez et al. (1997), é preciso que a temática ambiental esteja inserida em todos os segmentos da sociedade para que estes participem e apoiem a conservação, e valorizem as áreas naturais e as Unidades de Conservação. A comunidade do entorno, ao ser trabalhada no contexto ambiental, poderá ajudar a apoiar a conservação da área, ao entender melhor a importância de sua conservação. Produção de mudas para reflorestamento, reciclagem de resíduos e agricultura orgânica comunitária são exemplos de temas que também poderiam ser trabalhados com a população carente moradora do entorno.

\section{CONCLUSÕES}

A Estação Ecológica e a Floresta Estadual de Paranapanema são duas Unidades de Conservação contíguas, mas com objetivos de manejo diferentes. A E.Ec. Paranapanema por ser uma Unidade de Proteção Integral, tem como um dos objetivos básicos o desenvolvimento de atividades de educação ambiental, diferentemente do objetivo da Floresta Estadual, que é a produção florestal. A integração das duas Unidades permite ao visitante ter melhor entendimento das diferentes finalidades das duas áreas. A Estação Ecológica possui uma área com diferentes tipos de vegetação, importante para o desenvolvimento de atividades de educação ambiental, porém necessita de infraestrutura física, implantação de mais trilhas interpretativas com diferentes características ambientais, bem como recursos humanos devidamente capacitados para a realização destas atividades. É importante também que sejam ministrados as professores das escolas da região cursos de formação em educação ambiental, com o objetivo de habilitá-los para o desenvolvimento de atividades de educação ambiental nessa Estação Ecológica, ajudando a preservá-la.

\section{AGRADECIMENTOS}

Ao PqC Léo Zimback e ao PqC Roque Cielo Filho pelas informações prestadas e à PqC Marina Mitsue Kanashiro, pela elaboração das figuras 1 e 3.

\section{REFERÊNCIAS BIBLIOGRÁFICAS}

AGENDA 21. 1992. Disponível em: <http://www.mma.gov.br/responsabilidade-socioambiental/agenda-21>. Acesso em: 10 nov. 2015.

ANDRADE, W.J.; ROCHA, R.F. Manual de trilhas: um manual para gestores. IF Sér. Reg., n. 35, p. 1-74, 2008.

AOKI, H. et al. Plano de Manejo da Estação Ecológica de Paranapanema-SP. IF Série Reg., n. 23, p. 1-19, 2001.

ASSOCIAÇÃO BRASILEIRA DE NORMAS TÉCNICAS - ABNT. NBR 9050 de 31/05/2004: acessibilidade a edificações, mobiliário, espaços e equipamentos urbanos. Disponível em: < http://pfdc.pgr.mpf.mp.br/ atuacao-e-conteudos-de-apoio/legislacao/pessoa-deficiencia/norma-abnt-NBR-9050/view>. Acesso em: 20 mar. 2015. 
BRASIL. Constituição da República Federativa do Brasil. 1988. Disponível em: <http//www.planalto.gov.br/ ccivil_03/constituicao/constituicaocompilado.htm>. Acesso em: 20 set. 2015.

. Lei no 6.902, de 27 de abril de 1991. Dispõe sobre a criação de Estações Ecológicas, Áreas de Proteção Ambiental e dá outras providências. Disponível em: <http://www.planalto.gov.br/ccivil_03/leis/L6902.htm>. Acesso em: 23 jul. 2015.

Lei no 9.795, de 27 de abril de 1999. Dispõe sobre a Educação Ambiental, institui a Política Nacional de Educação Ambiental e dá outras providências. Disponível em: <http://www.mma.gov.br>. Acesso em: 22 set. 2014.

. Ministério do Meio Ambiente. Sistema Nacional de Unidade de Conservação da Natureza -

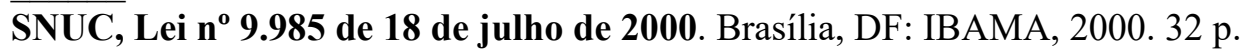

. Ministério do Meio Ambiente - MMA; Instituto Chico Mendes de Conservação da Biodiversidade ICMBio. Estratégia Nacional de Comunicação e Educação Ambiental no âmbito do Sistema Nacional de Unidades de Conservação - ENCEA. Brasília, DF: MMA, dez. 2009. 27 p.

CERVANTES, A.L.A. et al. Diretrizes para os programas de uso público do Instituto Florestal do Estado de São Paulo. In: CONGRESSO NACIONAL SOBRE ESSÊNCIAS NATIVAS, 2., 1992, São Paulo. Anais... São Paulo: UNIPRESS, 1992. p. 1076-1080. (Rev. Inst. Flor., v. 4, n. único, pt. 4, Edição especial).

CONFERÊNCIA RIO/ECO-92. 1992. Disponível em: <http//www.senado.gov.br/conferencia-rio-92-sobre-omeio-ambiente>. Acesso em: 22 set. 2015.

CONFERÊNCIA de Tbilisi. 1977. Disponível em: <http://www.ambiente.sp.gov.br/wp-content/uploads/cea/ Tbilisicompleto.pdf.>. Acesso em: 16 set. 2015.

DECLARAÇÃO da Conferência das Nações Unidas sobre o Meio Ambiente Humano - 1972. Disponível em: $<$ http://www.direitoshumanos.usp.br/index.php/Meio-Ambiente/declaracao-de-estocolmo-sobre-o-ambientehumano.html>. Acesso em: 14 out. 2015.

ENCONTRO de Belgrado. 1975. Disponível em: <http://www.portal.mec.gov.br/secad/arquivos/pdf/ educacaoambiental/historia.pdf>. Acesso em: 14 abr. 2015.

GRAZIANO, X.; LIMA, M. Criança ecológica: sou dessa turma. 2. ed. São Paulo: Secretaria de Estado do Meio Ambiente; Coordenadoria de Educação Ambiental; Assessoria de Comunicação, 2009. 104 p.

GUILlAUMON, J.R.; POLL, E.; SINGY, J.M. Análise das trilhas de interpretação. Bol. Técn. IF, n. 25, p. $1-57,1977$.

HERCULIANI, S. et al. Análise das atividades de educação ambiental realizadas no Parque Estadual Alberto Löfgren. Rev. Inst. Flor., v. 21, n. 2, p. 227-242, dez. 2009.

INSTITUTO CHICO MENDES DE CONSERVAÇÃO DA BIODIVERSIDADE - ICMBio. Parque Nacional de Itatiaia. Disponível em: <http://www.icmbio.gov.br/parnaitatiaia/>. Acesso em: 10 out. 2015.

LÜDKE, M.; ANDRÉ, A.D.E.M. Pesquisa em educação: abordagens qualitativas. São Paulo: EPU, 1986. 100 p.

MARCONDES, M.A.P. et al. Terminologia em manejo de unidades de conservação. IF Sér. Reg., n. 34, p. 1-63, 2008.

SÃO PAULO (Estado). Decreto Estadual no 40.992, de 06 de novembro de 1962. Plano de Ação. Dispõe sobre a desapropriação de imóvel situado no distrito e município de Paranapanema, comarca de Avaré, necessário ao Serviço Florestal da Secretaria da Agricultura. Disponível em: <http://www.al.sp.gov.br/ repositorio/legislacao/decreto/1962/decreto-40992-06.11.1962.html>. Acesso em: 20 set. 2015. 
SÃO PAULO (Estado). Decreto $n^{\circ} 37.538$, de 27 de setembro de 1993. Cria a Estação Ecológica de Paranapanema e dá providências correlatas. Disponível em: <http://www.jusbrasil.com.br/topicos/ 12721845/ decreto-n-37538-de-27-de-setembro-de-1993-de-sao-paulo>. Acesso em: 22 set. 2015.

. Decreto ${ }^{\circ} 51.453$, de 29 de dezembro de 2006. Cria o Sistema Estadual de Florestas - SIEFLOR e dá providências correlatas. Disponível em: <http://governo-sp.jusbrasil.com.br/legislacao/92176/ decreto-51453-06>. Acesso em: 22 ag. 2015.

Secretaria do Meio Ambiente. Resolução SMA no 59 de 27 de agosto de 2008. Regulamenta os procedimentos administrativos de gestão e fiscalização do uso público nas Unidades de Conservação de Proteção Integral do Sistema Estadual de Florestas do Estado de São Paulo, e dá outras providências. Disponível em: <http://www.ambiente.sp.gov.br/legislacao/.sma/resolucao-sma-59-2008>. Acesso em: 12 set. 2015.

TABANEZ, M.F. et al. Avaliação de trilhas interpretativas para educação ambiental. In: PÁDUA, S.M.; TABANEZ, M.F. (Org.). Educação ambiental: caminhos trilhados no Brasil. Brasília, DF: IPÊ, 1997. p. $89-102$.

TOLEDO, R.F.; PELICIONI, M.C.F. Educação ambiental em Unidades de Conservação. In: PHILIPPI Jr., A.; PELICIONI, M.C.F. (Ed.). Educação ambiental e sustentabilidade. Barueri: Manole, 2005. p. 749-769. (Coleção Ambiental, 3).

TRATADO de educação ambiental para sociedades sustentáveis e responsabilidade global. 1992. Disponível em: $<$ http://www.meioambiente.pr.gov.br/arquivos/File/coea/Tratado_Educacao_Ambiental.pdf $>$. Acesso em: 10 out. 2015.

VASCONCELLOS, J.M. de O. Educação e interpretação ambiental em Unidades de Conservação. Curitiba: Fundação O Boticário de Proteção à Natureza, 2006. 86 p. (Cadernos de Conservação, n. 4).

VENTURA, A.; BERENGUT, G.; VICTOR, M.A.M. Características edafo-climáticas das dependências do Serviço Florestal de São Paulo. Silvic. S. Paulo, v. 4, p. 57-140, 1965.

YELLOWSTONE ASSOCIATION. The official guide to touring the world's first national park. Yellowstone: Yellowstone Association, 2014. 94 p. 
Apêndice. Questionário

Appendix. Questionnaire

\section{ENTREVISTA COM GESTOR DA UNIDADE DE CONSERVAÇÃO}

Data

Nome:

Cargo:

\section{A- Estruturas físicas}

1- A Unidade de Conservação dispõe de estruturas físicas relacionadas à Educação Ambiental? Se sim, quais, e, se não, tem planejamento de implantar?

\section{B- Monitoria}

1- A Unidade conta com funcionários? Especificar quantidade, cargos, escolaridade, atividade executada, etc.

2- Qual o número de monitores na Unidade de Conservação?

3- Quais as características exigidas? (Formação acadêmica, curso, ano, habilidades, etc.).

4- Os monitores são estagiários ou são contratados? Qual é a duração do estágio?

5- Qual o tempo do contrato dos monitores?

6- Há rotatividade dos monitores? Estima quanto? Quais são as causas?

7- Há formação (treinamento) para os monitores? Como é realizada a formação? (Conteúdo, técnicas).

E quem dá o treinamento?

8- Há avaliação das atividades por eles desenvolvidas? Periodicidade.

9- Tem programa de estágio para cada estagiário?

10 - Se for um curso, pode disponibilizar o programa? Tem apostilas ou outro material didático? Quem ministra o curso?

\section{C- Educação Ambiental}

1- O que o gestor da Unidade de Conservação entende por Educação Ambiental?

2- São realizadas atividades de Educação Ambiental na Unidade de Conservação? Quais? Qual a frequência?

3- Qual é o público-alvo?

4- Quem planeja as atividades?

5- São realizadas atividades com os professores das escolas? (Cursos, palestras, etc.).

6- Tem os programas? Pode disponibilizar? Qual a frequência da realização das atividades?

7- São oferecidos cursos para alunos? Tem o programa? Pode disponibilizar?

8- Realiza atividades de Educação Ambiental com as comunidades do entorno? Quais atividades são realizadas? Tem o programa? Pode disponibilizar?

9- São realizados eventos comemorativos? Quais?

10- A população do entorno traz demandas para a Estação Ecológica? Quais? São atendidas?

11- A Estação Ecológica tem Conselho Consultivo constituído? Os membros do sistema de ensino participam das atividades exercidas? 
HERCULIANI, S. et al. Educação ambiental na Estação Ecológica de Paranapanema.

D- Unidade de Conservação e seu entorno

1- Há ONGs atuando junto à Unidade e/ou no entorno?

2- Como a comunidade local se relaciona com a Unidade? Interna e externa à Área?

3- Quais atividades econômicas são desenvolvidas nas proximidades? Há problemas ambientais decorrentes dessas atividades? Quais?

4- Há inter-relação da Unidade com a população da área de influência? Explique.

5-São desenvolvidos programas de caráter educativo na Unidade e nas comunidades vizinhas? Quais? Esses programas visam à maior integração e envolvimento da comunidade com a Unidade?

6- Há parcerias com órgãos públicos? E com a iniciativa privada? Se sim, quais?

E- Conflitos

1- A Unidade enfrenta conflitos de alguma natureza? Se sim, quais? Você identifica as estratégias para solucionar e/ou minimizar?

2- Há parcerias? Prefeitura? Empresas? 